\title{
Fibroadenoma of the Axilla in A Patient With Macroprolactinoma
}

\author{
Rafael Bandeira Lages ${ }^{\mathrm{a}}$, Theodoro Ribeiro Goncalves Neto ${ }^{\mathrm{a}}$, \\ Ravena Fontenele Belchior Cabral ${ }^{\mathrm{b}}$, Raissa Fontenele Belchior Cabral ${ }^{\mathrm{b}}$, \\ Ronald da Costa Araujo ${ }^{\mathrm{a}}$, Sabas Carlos Vieira ${ }^{\mathrm{a}, \mathrm{c}}$
}

\begin{abstract}
Ectopic breast tissues may be affected by to the same physiological and pathological alterations seen in the normal breast, including fibroadenoma. We report a 30-year-old nulliparous woman who presented with a left axillary lump, for which clinical impression of axillary lymphadenopathy was made. She was receiving treatment with cabergoline due to a prolactinoma with galactorrhea for some years, but her serum prolactin levels were still high. The patient underwent surgical resection of the nodule and the histology was identical to the fibroadenomas seen in the breast. To the best of our knowledge, this is the first report of fibroadenoma of the axilla in a patient with a macroprolactinoma. fibroadenoma in an ectopic breast tissue must be kept in mind in the differential diagnosis of axillary mass.
\end{abstract}

Keywords: Axilla; Breast diseases; Fibroadenoma; Prolactin; Prolactinoma

\section{Introduction}

Ectopic breast tissue occurs in 2 to $6 \%$ of the general population and is classically distributed along the embryonic milk line which extends from the axilla to the pubic region [1]. The axilla is the most common site, accounting for approxi-

Manuscript accepted for publication October 14, 2011

${ }^{a}$ Universidade Federal do Piaui (UFPI), Teresina, Piaui, Brazil.

${ }^{\mathrm{b}}$ Faculdade Integral Diferencial (FACID), Teresina, Piaui, Brazil.

${ }^{c}$ Corresponding author: Sabas Carlos Vieira, Rua Felix Pacheco 2159, Sala 305, Centro/Sul. Teresina, Piaui, Brasil.

Email: sabas.vieira@uol.com.br / rafaelblages@gmail.com

doi:10.4021/jmc384w mately 60 to $70 \%$ of accessory breast tissue [2]. The diagnosis of ectopic breast tissue is important because this tissue is also subject to the same alterations and diseases, whether benign or malignant, which affect naturally positioned breasts [3]. Although carcinoma of the axillary accessory breast is rare, accounting for $0.3 \%$ of all breast cancers, the most frequent condition in the accessory breast is breast cancer followed by mastopathy and fibroadenoma [4].

Since publications describing this anomaly are rare in literature, we decided to present a case of a 30-year-old woman with a subcutaneous tumor in the axilla that was histologically identical to the fibroadenoma seen in the breast. To the best of our knowledge, this is the first report of fibroadenoma of the axilla in a patient with a macroprolactinoma in the medical literature.

\section{Case Report}

A 30-year-old nulliparous woman presented with a painless growing tumor in the left axilla. She had normal breast development and no comorbidity. She never used contraceptive pills. There was no family history of breast cancer and polymastia.

On physical examination, we observed symmetric breasts and no masses or papillary discharge. In the left axilla, there

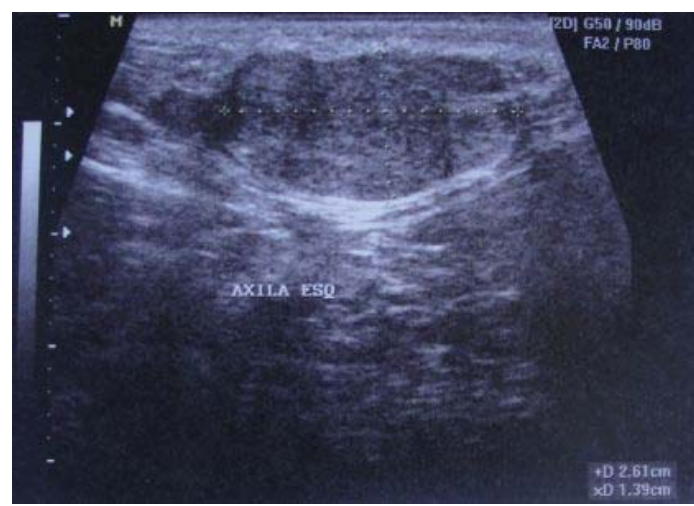

Figure 1. Ultrasonography of the left axilla showing a clearly circumscribed homogeneous solid nodule of $2.6 \times 1.4 \mathrm{~cm}$. 


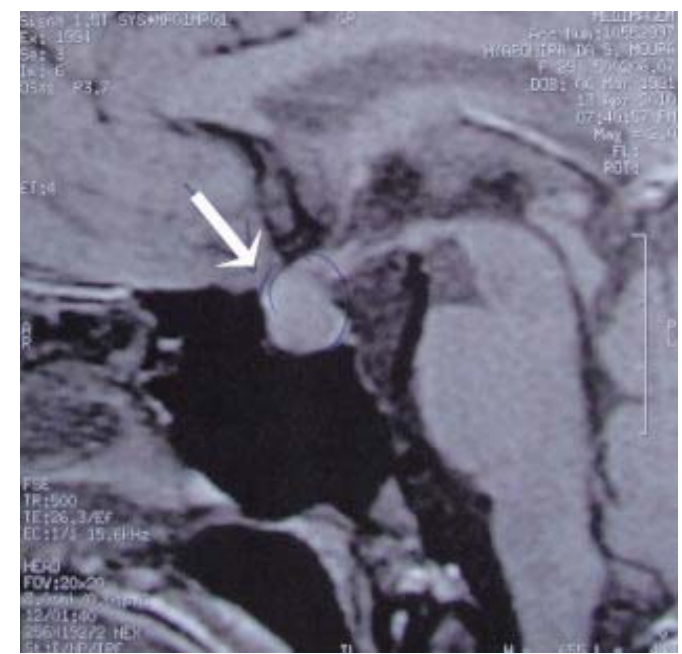

Figure 2. Cranial MRI sagittal view showing a macroadenoma of pituitary gland measuring $12 \times 11 \times 10 \mathrm{~mm}$ in diameter.

was a subcutaneous mass, freely mobile, well circumscribed, painless, with hard consistency and completely isolated from the left breast, looking like an enlarged lymph node of 2.5 $\mathrm{cm}$. There was no associated nipple, areola or skin changes. No similar alterations were found in other parts of her body. An ultrasonography of the left axilla revealed a clearly circumscribed homogeneous solid nodule with a diameter of 2.6 x 1.7 x 1.4 cm (Fig. 1), like a lymphadenopathy. No evidence of supernumerary breast tissue was seen.

Our patient was receiving treatment with cabergoline due to a prolactinoma with galactorrhea for some years, but her prolactin levels were still high (35 micrograms/liter). A cranial magnetic resonance imaging (mri) revealed a macroadenoma of pituitary gland measuring 12 × 11 x $10 \mathrm{~mm}$ in diameter (Fig. 2).

The patient underwent surgical resection of the nodule in axilla and all clinically visible tumor was totally excised (Fig. 3). Histopathological examination revealed the diagnosis of intracanalicular type of fibroadenoma, identical to

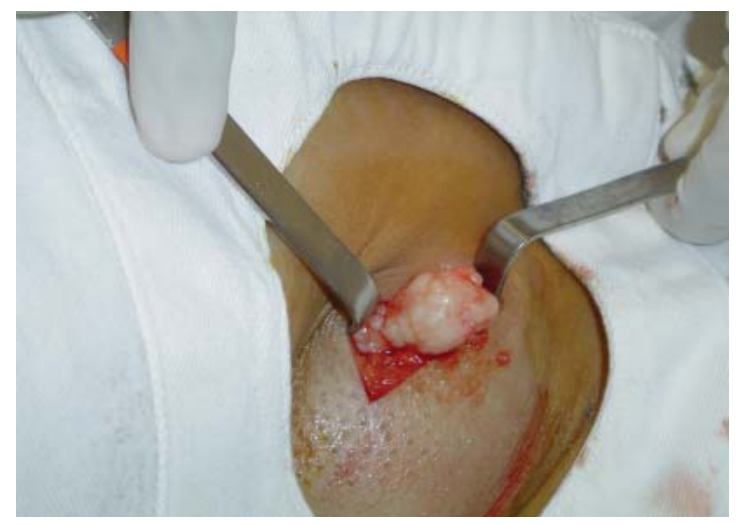

Figure 3. Excision of the nodule in axilla. those seen in the eutopic mammary tissue. The patient is currently undergoing follow-up and remains asymptomatic six months after the surgery.

\section{Discussion}

The differential diagnosis for a solitary axillary mass is very broad, including breast parenchymal lesions, lymph nodes, and infectious and vascular lesions, as well as an axillary tail of spence (extension of normal parenchyma towards the axilla) or a torn muscle belly. It is important to differentiate benign from malignant axillary masses to avoid unnecessary concern and intervention [1, 3, 5].

The possibilities of malignant masses include breast cancer, rhabdomyosarcoma, epidermoid carcinoma, neuroendocrine tumors, lymphoma, and melanoma. axillary lymph node metastases from carcinoma of the breast (or of another cancer) are the single most important abnormality to exclude, as they are an important prognostic factor in breast cancer. Benign lesions can include sebaceous cysts, lipomas, and vascular lesions. Among infectious causes, there are suppurative hidradenitis, cat-scratch disease, reactive lymphadenitis or lymphadenopathy secondary to any upper extremity infection, and tuberculosis $[1,5,6]$.

Muttarak et al [7] retrospectively reviewed mammograms and pathological results of 43 consecutive patients who presented with palpable unilateral masses in the axilla but who had normal breasts on physical examination. Of the 43 patients, 40 had axillary lymphadenopathy while three had lipoma, fibroadenoma and haematoma, respectively. Causes of malignant lymphadenopathy $(\mathrm{n}=22)$ were metastatic diseases from non-mammary primary malignancy (n $=8$ ), Occult ipsilateral breast carcinoma $(n=5)$, and previous contralateral breast carcinoma $(n=9)$. Causes of benign lymphadenopathy $(n=18)$ were reactive nodal hyperplasia $(n=6)$, collagen vascular diseases $(n=2)$, and acute bacterial $(\mathrm{n}=2)$ and tuberculous $(\mathrm{n}=8)$ lymphadenitis. According to the author, it was difficult to differentiate between benign and malignant lymphadenopathy on the basis of mammographical findings alone [7].

As the most common locate of the ectopic breast tissue is in the axilla, supernumerary breasts and breast-associated tumors should be kept in mind in the management of patients with axillary mass as a sole clinical feature. When present without a nipple or areola, as reported in our case, it can be a diagnostic problem.

The excisional biopsy was made because there was no evidence of supernumerary breast tissue and we preoperatively diagnosed the axillary mass as possible enlarged lymph node. Tumors in supernumerary breast tissue should be diagnosed using the same methods applied to normal breast tissue (mammography, ultrasonography, cytology and biopsy), with observation of specific indications. However, 


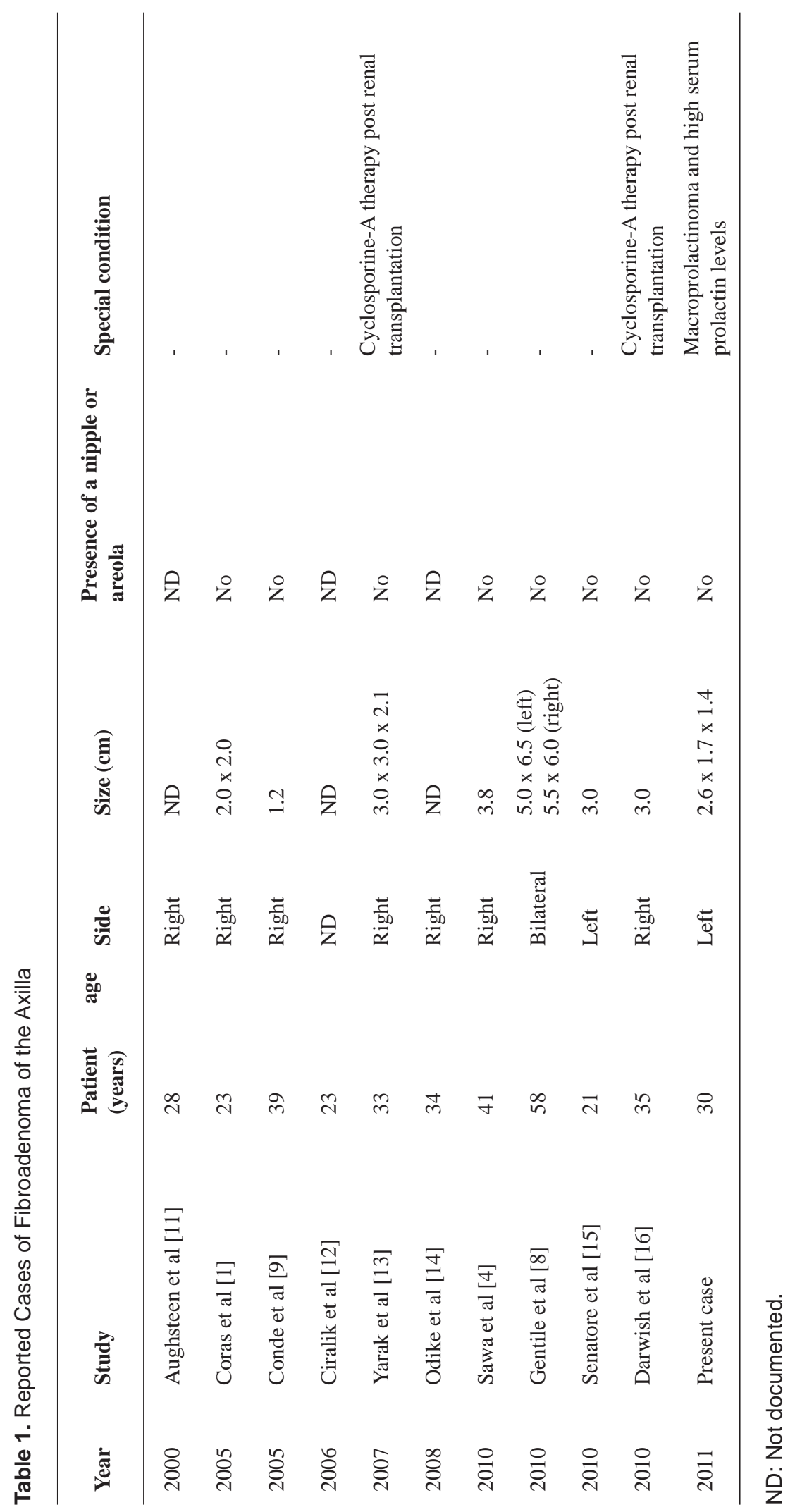


due to the low incidence of such tumors, diagnosis may be delayed or even ignored, thus making treatment more difficult. When tumors or nodules are found along the mammary line, the presence of breast tissue should be considered during the investigation [8. 9].

Fibroadenoma is a frequent cause of benign tumors in young women. Since they arise from lobules, it is not surprising that these are seen predominantly in women in the 15-25 age group, even though they may be diagnosed later [10]. However, it rarely is described in axillary supernumerary breasts [2]. We conducted a systematic literature review regarding case reports of fibroadenoma in axilla by searching pubmed, using the following terms: "axillary breast" and "fibroadenoma" / "ectopic breast” and "fibroadenoma” / "axilla” [and] "fibroadenoma” / "supernumerary breast” and "fibroadenoma”. We included all case reports of fibroadenoma in axilla with available abstract, totalizing 10 reports (Table 1$)$ [1, 4, 8, 9, 11-16]. The patients' average age was 33.2 years (minimum of 21 and maximum of 58 years), and the mean lesion size was $3.5 \mathrm{~cm}$. the most common site of axillary fibroadenoma was the right side. In one of the cases, it was reported bilateral axillary fibroadenoma [8].

Yarak et al [13] and Darwish et al [16] reported cases of fibroadenoma in accessory mammary tissue in kidney transplant recipients using Cyclosporine-A. This is one of the drugs that inhibits T-cell activation via calcineurin inhibition. The Cyclosporine-A blocks the prolactin receptors in $\mathrm{T}$ and B lymphocytes, thus inhibiting the action of prolactin. Consequently, there is an in increase in prolactin blood levels, suggesting influence in the steroidogenic function of the ovary and thus affecting the physiological state of the breast. Its chronic use could develop malignant cutaneous tumors and benign mucocutaneous proliferative diseases (fibroadenomas, hypertrichosis, gingival hypertrophy, papillomas, sebaceous hyperplasia and epidermic cysts) [13, 16].

It should be noted that our patient had a macroprolactinoma and despite being in treatment he had high serum prolactin levels. Prolactin plays an important role in the proliferation and differentiation of normal breast and its receptors are present in about $50 \%$ of cases of fibroadenoma, but there are no data concerning their potential implications in fibroadenoma physiopathology [10]. Ginsburg et al demonstrated that prolactin is synthesized by human mammary tumor cell lines, and that neutralizing anti-prl antibodies inhibit cell proliferation [17]. These observations were the first arguments to suggest the existence of locally produced prolactin stimulating cell proliferation via an autocrine-paracrine loop. Since expression of the prolactin receptors is increase in fibroadenomas, it is possible that prolactin plays an important role in breast tumor growth $[10,18,19]$.

In conclusion, fibroadenoma must be kept in mind in the differential diagnosis of axillary swellings. When the mass is found in mammary ridge, the presence of ectopic breast tissue must be considered. In addition, further researches should seek to establish the potential implications of high serum prolactin levels in the pathophysiology of fibroadenoma.

\section{References}

1. Coras B, Landthaler M, Hofstaedter F, Meisel C, Hohenleutner U. Fibroadenoma of the axilla. Dermatol Surg. 2005;31(9 Pt 1):1152-1154.

2. Burdick AE, Thomas KA, Welsh E, Powell J, Elgart GW. Axillary polymastia. J Am Acad Dermatol. 2003;49(6):1154-1156.

3. Mukhopadhyay M, Saha AK, Sarkar A. Fibroadenoma of the ectopic breast of the axilla. Indian J Surg 2010;72:143-145.

4. Sawa M, Kawai N, Sato M, Takeuchi T, Tamaki T, Oura S. Fibroadenoma of the axillary accessory breast: diagnostic value of dynamic magnetic resonance imaging. Jpn J Radiol. 2010;28(8):613-617.

5. Yang WT, Suen M, Metreweli C. Mammographic, sonographic and histopathological correlation of benign axillary masses. Clin Radiol. 1997;52(2):130-135.

6. de Andrade JM, Marana HR, Sarmento Filho JM, Murta EF, Velludo MA, Bighetti S. Differential diagnosis of axillary masses. Tumori. 1996;82(6):596-599.

7. Muttarak M, Chaiwun B, Peh WC. Role of mammography in diagnosis of axillary abnormalities in women with normal breast examination. Australas Radiol. 2004;48(3):306-310.

8. Gentile P, Izzo V, Cervelli V. Fibroadenoma in the bilateral accessory axillary breast. Aesthetic Plast Surg. 2010;34(5):657-659.

9. Conde DM, Torresan RZ, Kashimoto E, Carvalho LE, Cardoso Filho C. Fibroadenoma in axillary supernumerary breast: case report. Sao Paulo Med J. 2005;123(5):253-255.

10. Courtillot C, Plu-Bureau G, Binart N, Balleyguier C, Sigal-Zafrani B, Goffin V, Kuttenn F, et al. Benign breast diseases. J Mammary Gland Biol Neoplasia. 2005;10(4):325-335.

11. Aughsteen AA, Almasad JK, Al-Muhtaseb MH. Fibroadenoma of the supernumerary breast of the axilla. Saudi Med J. 2000;21(6):587-589.

12. Ciralik H, Bulbuloglu E, Arican O, Citil R. Fibroadenoma of the ectopic breast of the axilla--a case report. Pol J Pathol. 2006;57(4):209-211.

13. Yarak S, Floriano M, Decico JE, Konishi CT, Michalany NS, Enokihara MY, Tomimori-Yamashita J. First report of a fibro-adenoma in axillary mammary tissue of a renal transplant patient taking cyclosporin. Int J Dermatol. 2007;46(4):407-409.

14. Odike MA, Orakwe JC, Oguejiofor OC, Odenigbo UC, 
Onyiaorah IV. Axillary fibroadenoma mimicking lymphadenopathy. Niger J Clin Pract. 2008;11(1):72-73.

15. Senatore G, Zanotti S, Cambrini P, Montroni I, Pellegrini A, Montanari E, Santini D, et al. Ectopic breast fibroadenoma. Case report. G Chir. 2010;31(3):96-99.

16. Darwish A, Nasr AO, El Hassan LA, Fahal AH. Cyclosporine-A therapy-induced multiple bilateral breast and accessory axillary breast fibroadenomas: a case report. J Med Case Reports. 2010;4:267.
17. Ginsburg E, Vonderhaar BK. Prolactin synthesis and secretion by human breast cancer cells. Cancer Res. 1995;55(12):2591-2595.

18. Clevenger CV, Plank TL. Prolactin as an autocrine/ paracrine factor in breast tissue. J Mammary Gland Biol Neoplasia. 1997;2(1):59-68.

19. Clevenger CV, Furth PA, Hankinson SE, Schuler LA. The role of prolactin in mammary carcinoma. Endocr Rev. 2003;24(1):1-27. 